\title{
Garlic: From treatment to disease
}

\author{
Nassiba Zerrouki ${ }^{1}$, Loubab Omahsan ${ }^{1}$, Siham Dikhaye ${ }^{1,2}$, Nada Zizi ${ }^{1,2}$
}

${ }^{1}$ Department of Dermatology, University of Mohammed First, Faculty of Medicine and Pharmacy, Mohammed 6 University Hospital of Oujda, Morocco, ${ }^{2}$ Epidemiology Laboratory for Clinical Research and Public Health, University of Mohammed First, Faculty of Medicine and Pharmacy, Mohammed 6 University Hospital of Oujda, Morocco

Corresponding author: Dr. Nassiba Zerrouki, E-mail: zerrouki.nassiba@gmail.com

\begin{abstract}
Garlic belongs to the family Alliaceae. As a condiment, garlic is added to food to improve its flavor. Therapeutic uses have also been reported for some of garlic components that are allyls with disulfide and thiol groups. Case reports have highlighted the possibility that garlic use may cause allergic reactions. We report a new case of irritative dermatitis due to the application of garlic.
\end{abstract}

Key words: Garlic; Allergic, Reaction

\section{INTRODUCTION}

Garlic is one of the best-researched/best-selling herbal remedies and is also commonly used as a food and a spice. Pharmacological actions of garlic include antibacterial, antiviral, antifungal, antihypertensive, blood glucose lowering, antithrombotic, antimutagenic and antiplatelet actions. Traditionally, garlic has been used both orally and topically most consistently perhaps to prevent and treat infections and as a way of maintaining general health [1]. Case reports have highlighted the possibility that garlic use may cause allergic reactions. We report a new case of irritative dermatitis due to the application of garlic.

\section{CASE REPORT}

A 22 years old patient was presenting a history of personal atopy (allergic rhinitis and conjunctivitis). After having a "prescription" from a radio show, he applied a Garlic juice on the face without solar exposure. One day later, she developed a burning sensation, pain, itch and erythema, he subsequently developed multiple bullae (Fig. 1). A diagnosis of dermatitis irritative was made, with a complete resolution of her symptoms after symptomatic treatment (Fig. 2).

\section{DISCUSSION}

Garlic belongs to the family Alliaceae. The allergenic potential of garlic is well recognized, and allergens have been identified as diallyl disulfide (which is considered to be the primary allergen), allylpropyl sulfide and allicin (the latter may be an irritant) [1]. Garlic also contains a not-yet identified high molecular-weight protein that presumably leads to systemic allergic [2].

Case reports of allergic reactions associated to garlic use include allergic contact dermatitis, generalized urticaria, angiedema pemphigus and anaphylaxis [1]. Allergic contact dermatitis is a delayed type IV allergic reaction of the skin with varying degrees of erythema, edema, and vesiculation resulting from cutaneous contact with a specific allergen [2].

The possibility that garlic may cause irritant contact dermatitis (known as "garlic burns") has been highlighted by a number of case reports/case series, both in infants and in adults [1]. Compared to infants, a longer exposure time seems to be generally needed for causing burns in adults. The cases involved the feet, wrists, hand, trunk, breast, and forehead. It is responsible for a particular dermatitis: pulpitis of the first 3 fingers. The localization at the level of the face is rare. Atopic terrain is frequently found. The garlic was applied to treat asthma, skin lesions, pain, and fever, and in some instance. Garlic

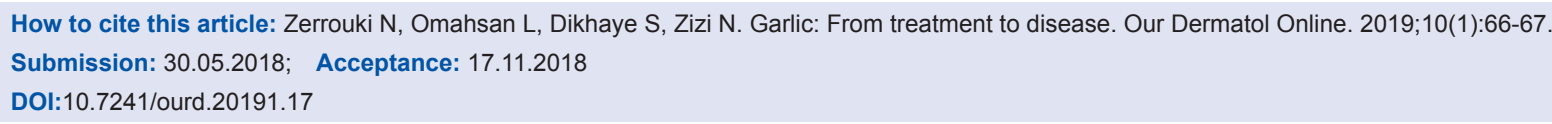



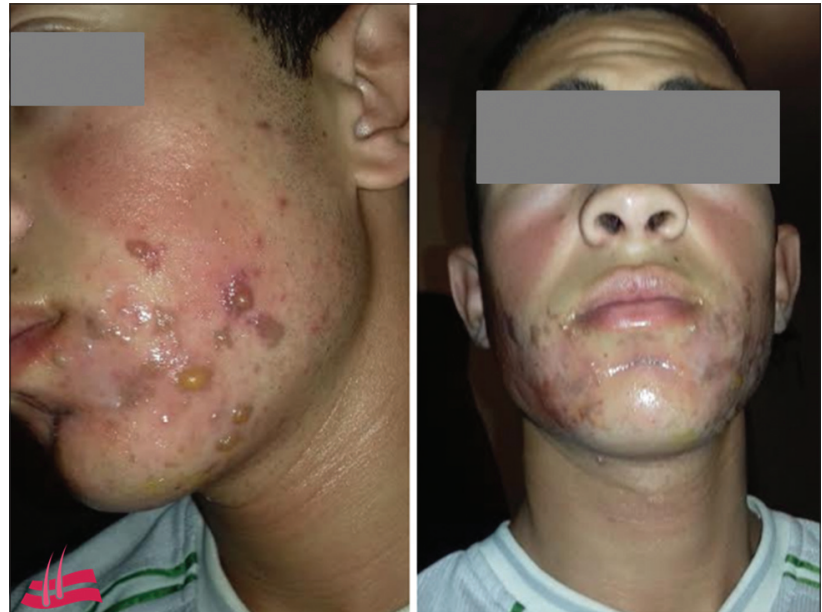

Figure 1: Erythematous and bullous lesions after application of garlic.

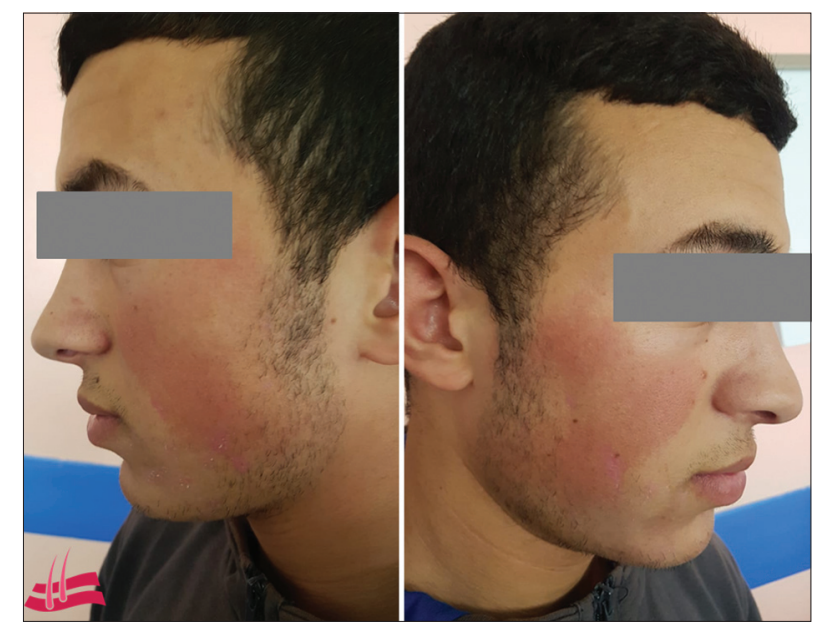

Figure 2: Clinical aspect after treatment. burns have been also induced for self-mutilation in order to avoid military duty or without a precise rational motive $[3,4]$. In all cases, the burns were successfully managed with conservative treatment alone [4].

\section{CONCLUSION}

Despite a very high consumption and use of garlic in the world, published cases of irritative dermatitis are rare.

\section{Consent}

The examination of the patient was conducted according to the Declaration of Helsinki principles.

\section{REFERENCES}

1. Borrelli F. Garlic (Allium sativum L.): Adverse effects and drug interactions in humans. Mol Nutr Food Res. 2007;51:1386-97.

2. Beaumont P, Moneret-Vautrin DA, Dzviga C, Grand J-L. Severe anaphylaxis to onion and garlic: Lack of efficiency of prick tests and specific IgEs to the allergenic source. A series of five cases. Rev Fran d'Allergol. 2013;53:446-9.

3. Lachter J, Babich JP, Brookman JC, Factor AY. Garlic: a way out of work. Mil Med. 2003;168:499-500.

4. Friedman T, Shalom A, Westreich M. Self-inflicted garlic burns: our experience and literature review. Int J Dermatol. 2006;45:1161-3.

Copyright by Nassiba Zerroukij, et al. This is an open-access article distributed under the terms of the Creative Commons Attribution License, which permits unrestricted use, distribution, and reproduction in any medium, provided the original author and source are credited.

Source of Support: Nil, Conflict of Interest: None declared. 